\title{
A EXPERIÊNCIA DO PROJETO-DESAFIO NO ENSINO-APRENDIZAGEM DA METODOLOGIA DIAMANTE-DUPLO NO CURSO DE DESIGN
}

\section{THE PROBLEM-BASED LEARNING EXPERIENCE IN TEACHING OF THE DOUBLE-DIAMOND METHODOLOGY IN THE DESIGN COURSE}

\author{
Felipe Zanette da Silveira ${ }^{1}$ \\ Bárbara Regina Alvarez ${ }^{2}$ \\ Fabio Costa Brodbeck ${ }^{3}$ \\ Beatriz D'Agostin Donadel ${ }^{4}$ \\ João Luís Silva Rieth ${ }^{5}$
}

\begin{abstract}
RESUMO: Este artigo tem como finalidade descrever o processo de ensino aplicado a disciplina de Projeto de Produto V (P5) do curso de Graduação em Design da Universidade do Extremo Sul Catarinense (UNESC). Durante o semestre letivo foi aplicado a metodologia de ensino pela pesquisa (problem-based learning - $P B L$ ) tendo como objetivo solucionar a demanda de um cliente externo. Para isso, os acadêmicos trabalharam de forma individual e coletiva baseando-se nas etapas do diamante duplo (Double Diamond), tema foco da disciplina, para obtenção da solução formal do problema, que consiste no desenvolvimento de um produto. Ao final do semestre todas equipes obtiveram diferentes soluções ao problema proposto. As soluções foram então modeladas e apresentadas fechando assim o ciclo do diamante duplo e PBL com a entrega da solução do problema proposto.
\end{abstract}

PALAVRAS-ChAVE: Design, Desenvolvimento de produtos, Diamante Duplo, Projeto desafio.

ABSTRACT: The purpose of this article is to describe the teaching process applied to the Product Design V (P5) of the Design course at the Extreme South Catarinense University (UNESC). During the semester, the PBL (problem-based learning) methodology was applied

\footnotetext{
${ }^{1}$ Grupo de pesquisa em Projeto de Produtos - Universidade do Extremo Sul Catarinense - UNESC. E-mail: fzs@unesc.net

${ }^{2}$ Grupo de pesquisa em Exercício e Saúde GEPES - Universidade do Extremo Sul Catarinense - UNESC, Criciúma, Brasil.

${ }^{3}$ Curso de Design - Universidade do Extremo Sul Catarinense - UNESC, Criciúma, Brasil.

${ }^{4}$ Curso de Pedagogia, Centro Educacional Barriga Verde - UNIBAVE, Orleans, Brasil.

${ }^{5}$ Grupo de pesquisa em Projeto de Produtos - Universidade do Extremo Sul Catarinense - UNESC, Criciúma, Brasil.
}

Saberes Pedagógicos, Criciúma, v. 3, nº1, janeiro/junho 2019.- Curso de Pedagogia- UNESC 
to solve the demand of an external customer. The academics worked individually and collectively, based on the steps of Double Diamond, theme of the discipline, to obtain the formal solution of the problem. At the end of the semester all teams obtained different solutions to the proposed problem. The solutions were innovation products, and the teams produced physicals models for show it. This step closes the double diamond and PBL cycle with the delivery of the solution of the proposed problem.

KEYWORDS: Design, Products developed, Double diamond, problem-based learning.

\section{INTRODUÇÃO}

O presente relato tem como objetivo apresentar a experiência de ensino da disciplina de Projeto de Produto V (P5), no curso de Graduação em Design da Universidade do Extremo Sul Catarinense (UNESC), onde, por meio da aplicação da didática do Aprendizado pelo Desafio (Problem-Based Learning - PBL), conduziu-se o ensino-aprendizagem da chamada "Metodologia Diamante Duplo".

O aprendizado pelo desafio é atualmente muito discutido no ensino da engenharia. Este método conduz os estudantes na identificação de um problema pré-determinado, e os acompanham na busca das possíveis soluções a partir da abordagem do conteúdo da disciplina (MAYER, 2013). Tal metodologia altera a ordem tradicional do ensino e traz o acadêmico para o centro do problema, fazendo com que este se aproprie e aplique o conhecimento na formulação da resposta do desafio. Segundo Donoso-Garcia e Tôrres, (2007, p.1), “o elementochave desta metodologia de ensino é a solução de problemas como força motriz para apreensão de conceitos e integração de conhecimentos". Dessa forma é possível entender que a escolha do Projeto Desafio a ser proposto pelos professores é elemento chave para o sucesso do processo de ensino-aprendizagem. A Figura 1 mostra de forma esquemática o princípio de trabalho da metodologia PBL.

Diferente de uma aula prática tradicional em laboratório, onde o acadêmico segue à risca um percurso pré-elaborado, repetindo, por exemplo, um experimento cujo resultado já é conhecido; o PBL busca o trabalho em grupo, bem como o reconhecimento das habilidades individuais dos participantes, promovendo autonomia e incentivando a liderança. Suas atividades estimulam o aluno a trilhar caminhos desconhecidos, buscando desenvolver

Saberes Pedagógicos, Criciúma, v. 3, nº1, janeiro/junho 2019.- Curso de Pedagogia- UNESC 
tecnologias distintas e inovadoras como solução. Dessa forma, por meio do desenvolvimento de um projeto norteador, o aprendizado pelo desafio almeja promover uma interface interativa entre empresa/comunidade/universidade, estabelecendo um importante papel no desenvolvimento regional (DONOSO-GARCIA; TÔRRES, 2007; FINK, 2002). O Quadro 1 mostra um resumo comparativo acerca das diferenças entre as metodologias convencionais e o aprendizado pelo desafio.

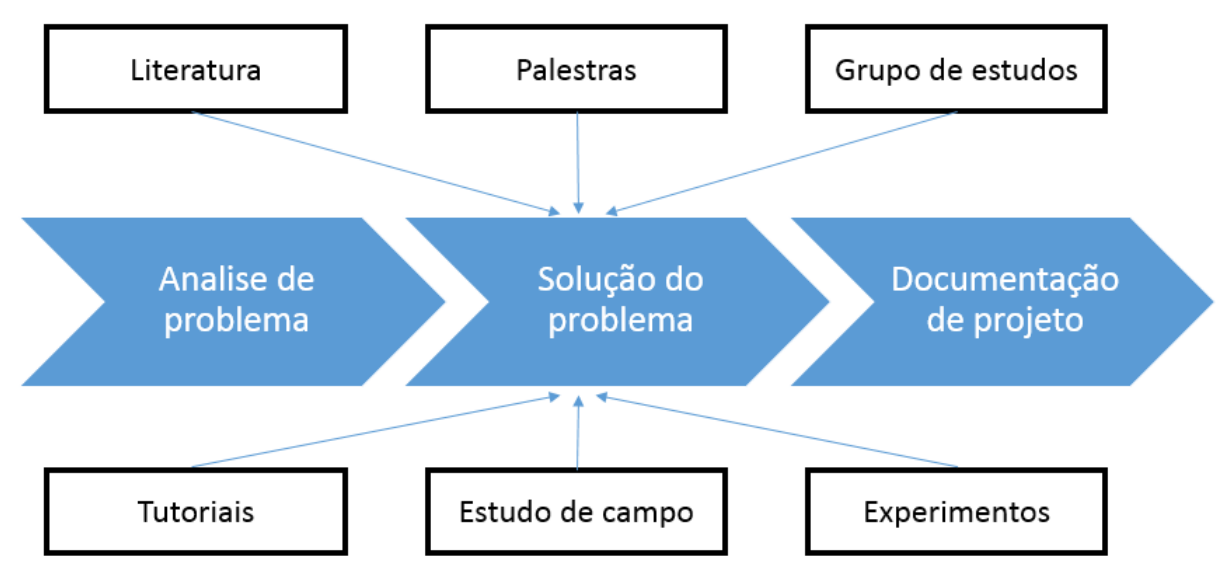

Figura 1: Princípio de trabalho da metodologia PBL. Fonte: FINK (2002, p.2):

\begin{tabular}{|c|c|}
\hline Metodologias convencionais & $\underline{\text { Aprendizado pelo Desafio }}$ \\
\hline Conhecimento como prescrição & Conhecimento como experiência \\
\hline O Centro é o professor/especialista & O centro é o aluno/estudante \\
\hline Linear e Racional & Coerente e relevante \\
\hline Organizada das partes constituintes para & Organizada do todo para as partes \\
o todo & constituintes \\
\hline Ensinar é transmitir & Ensinar é facilitar \\
\hline Aprender é receber & Aprender é construir \\
\hline Ambiente estruturado & Ambiente flexível \\
\hline Quadro l: Relação entre as Metodologias convencionais e o Aprendizado pelo Desafio.
\end{tabular}

Quadro 1: Relação entre as Metodologias convencionais e o Aprendizado pelo Desafio. Fonte: DONOSO-GARCIA e TÔRRES (2007, p.2).

Saberes Pedagógicos, Criciúma, v. 3, nº1, janeiro/junho 2019.- Curso de Pedagogia- UNESC 
Vale ressaltar que embora o método de ensino por meio de projetos tenha evidentes qualidades que podem proporcionar ao aluno uma melhor aprendizagem, ele exige do professor habilidades específicas e "custos", que devem ser previstos:

(...) o aprendizado pelo desafio, quando bem implementado, seguramente implica em aumento de carga de trabalho para os professores envolvidos, tendo em vista a quantidade de projetos executados em paralelo, as diferentes necessidades de diferentes grupos de alunos, e os problemas práticos não previstos decorrentes da natureza intrínseca do procedimento. Este é o "custo" de uma melhoria substancial na qualidade da formação de nossos alunos. (DONOSO-GARCIA; TÔRRES, 2007, p.3).

A metodologia aplicada no desenvolvimento de produtos chamada Diamante Duplo é um esquema organizacional aberto que tem como objetivo manter o foco do pesquisador na ação exigida, evitando perder-se no processo criativo de desenvolvimento, e consequentemente, aumentando a eficiência na busca da rápida convergência ao produto final. Vale destacar que se trata de uma metodologia aberta, onde cada etapa básica pode se repartir em outras etapas menores, que por sua vez, podem fazer uso de ferramentas auxiliares para serem cumpridas.

Segundo DESIGN COUNCIL (2016), o Diamante Duplo consiste basicamente de quatro principais etapas:

Entendimento: levantamento e compreensão do mercado, do usuário, e de todas as outras variáveis que possam interferir diretamente no produto.

Definição: análise dos dados pesquisados na etapa anterior e definição sobre o planejamento e gerenciamento do projeto. Ainda nesta etapa é definido a ideia central (briefing) que norteará o desenvolvimento do produto.

Desenvolvimento: desenvolvimento criativo e funcional do produto, esta etapa é finalizada com a realização de testes em protótipos.

Entrega: lançamento do produto no mercado, e o início de um ciclo contínuo (looping) iniciado pelas avaliações e feedback dos usuários, que podem sugerir adequações, mudanças e melhoramentos futuros.

A Figura 2 mostra a representação gráfica do processo metodológico, e as etapas descritas acima.

Entre as ferramentas auxiliares que se tem disponível para uso, podemos destacar a matriz morfológica. Esta ferramenta é uma forma de organizar os atributos de produtos com

Saberes Pedagógicos, Criciúma, v. 3, nº1, janeiro/junho 2019.- Curso de Pedagogia- UNESC 


\section{SABERES PEDAGÓGICOS}

Revista do Curso de Graduaçào de Pedagogia - Unesc

ISSN 2526-4559

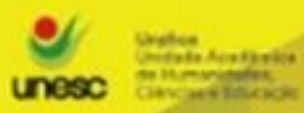

uso ou aplicação similares ao produto a ser desenvolvido em forma de matriz, para facilitar a busca de melhoria das qualidades estéticas e funcionais no projeto final (PAHL e BEITZ, 1996 apud SANTOS, 2009). Tal ferramenta foi incorporada no processo de desenvolvimento para incentivar a busca pela inovação. Um exemplo de matriz morfológica pode ser observado na Figura 3.

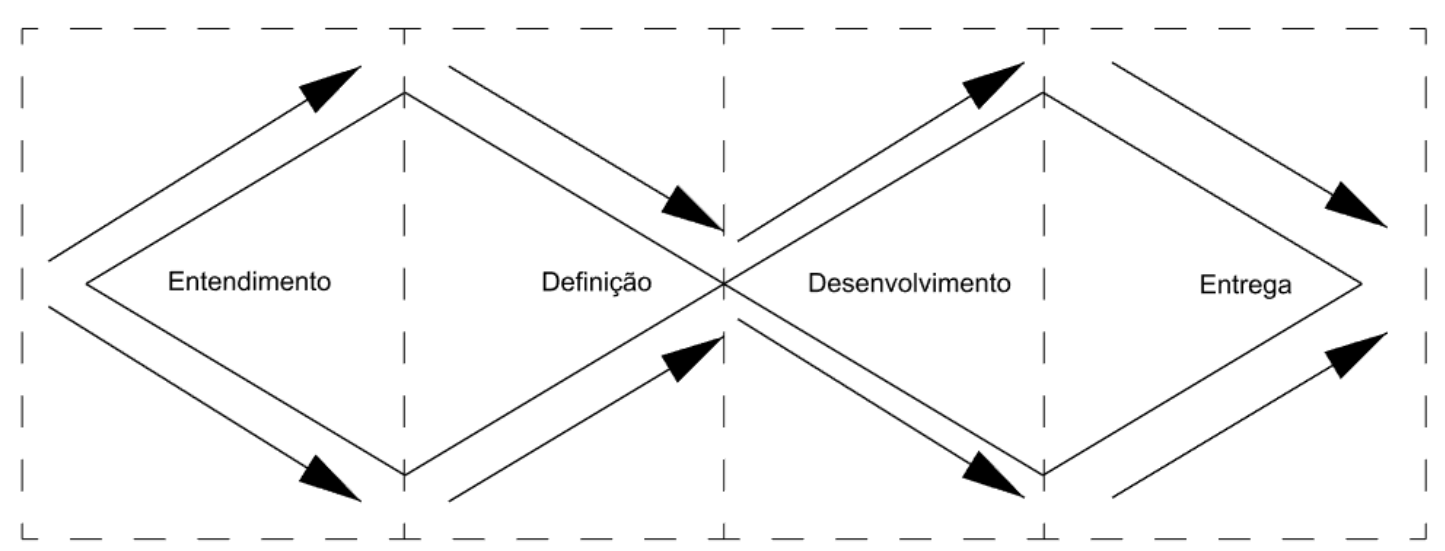

Figura 2: Metodologia Diamante Duplo

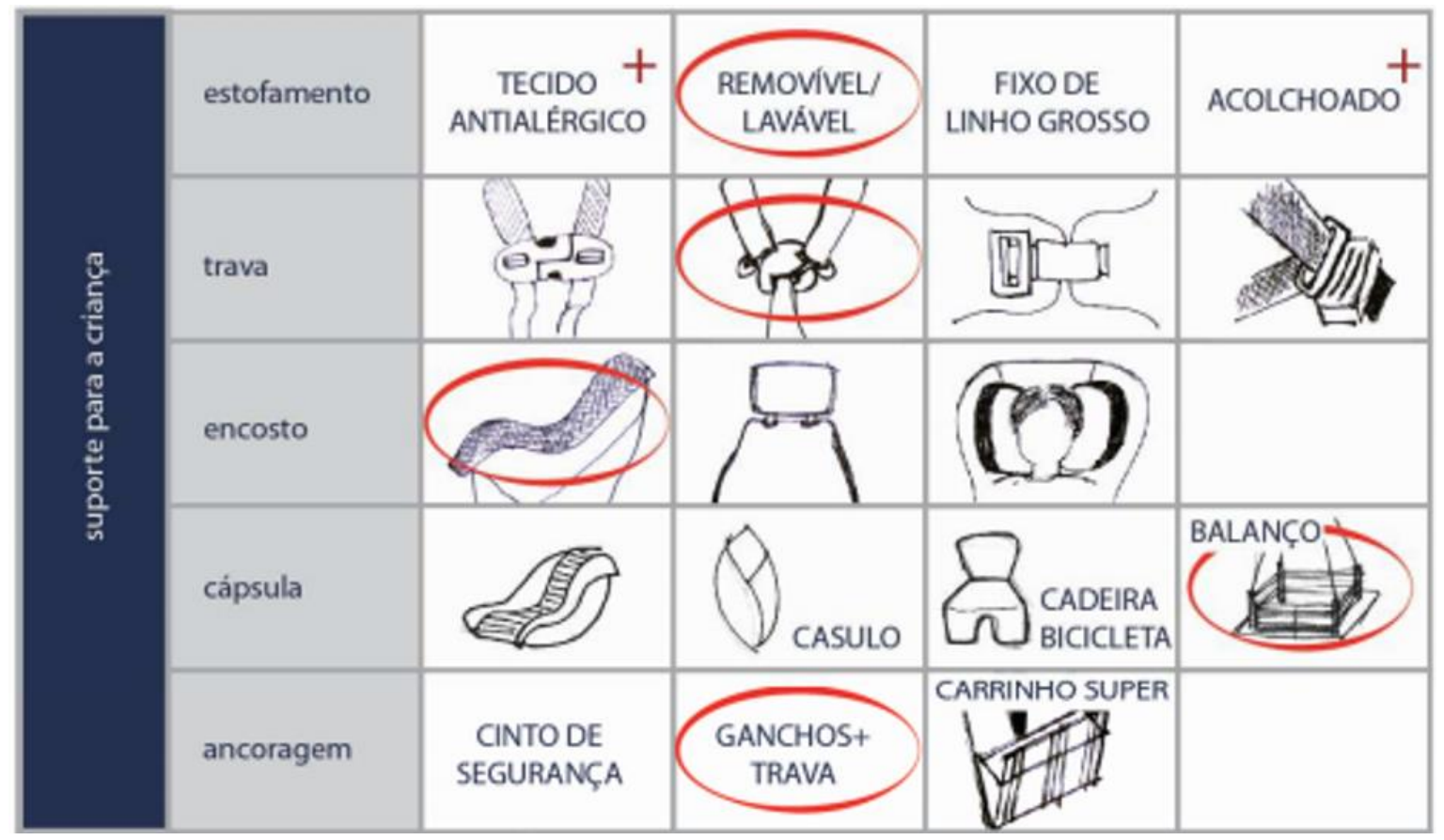

Figura 3 Exemplo de Matriz Morfológica para desenvolvimento de carrinho de bebê.

Saberes Pedagógicos, Criciúma, v. 3, nº1, janeiro/junho 2019.- Curso de Pedagogia- UNESC 


\section{SABERES PEDAGÓGICOS}

Revista do Curso de Graduaçào de Pedagogia - Unesc

ISSN $2526-4559$

Fonte: (ZAVADIL et al., 2014)

\section{METODOLOGIA}

Este relato de experiência constituiu-se a partir das observações registradas pelos professores envolvidos nas atividades da disciplina de Projeto de Produto V (P5) durante um semestre letivo, e posteriormente, em reflexões sobre os aspectos didático-pedagógicos evidenciados no referido percurso formativo.

Projeto de Produto V é uma disciplina ministrada na $7^{\mathrm{a}}$ fase do curso de Design, e visa o desenvolvimento de produtos industriais de média complexidade por meio da aplicação de metodologias próprias ao desenvolvimento de produtos. A equipe de professores envolvidos possui especialidades diversas, aliando, por exemplo, o designer; a engenharia; e a ergonomia. Esta equipe multidisciplinar aproxima os acadêmicos de uma experiência real encontrada no mercado de trabalho, onde a pesquisa e o desenvolvimento de produtos é resultado do trabalho de equipes com diversas especialidades.

Há décadas as discussões sobre didática no ensino superior têm apontado a urgência de promover o processo de pesquisa nos alunos, para que deixem de ser objeto de ensino e se tornem parceiros de trabalho, sujeitos capazes não só de aprender a fazer, mas de inventar e reinventar práticas em um processo contínuo de construção e reconstrução do conhecimento (DEMO,1997). Ao longo deste relato sobre a metodologia do ensino pelo Projeto Desafio desenvolvida na disciplina P5, buscou-se destacar aproximações e diálogo com perspectivas educacionais que entendem a pesquisa, como prática privilegiada de construção de conhecimento.

As metodologias de trabalho para o desenvolvimento de produtos são diversas. No desenvolvimento da disciplina P5, os alunos puderam compreender e aplicar a metodologia do Diamante Duplo na elaboração da solução ao desafio proposto. No relato dessa experiência de ensino, buscou-se destacar a relação existente entre a metodologia didática proposta pelos docentes na disciplina do Curso de Design - a proposta do Projeto Desafio; e a aprendizagem, 
por parte dos alunos, sobre a metodologia de desenvolvimento de produto ensinada - a metodologia do Diamante Duplo.

A Figura 4 mostra esquematicamente o processo didático-pedagógico aplicado na disciplina, tendo o Projeto Desafio como elemento-chave para o ensino-aprendizagem do Diamante Duplo, conteúdo da disciplina. Por meio da aplicação do conteúdo ensinado os alunos obtêm a solução do desafio proposto.

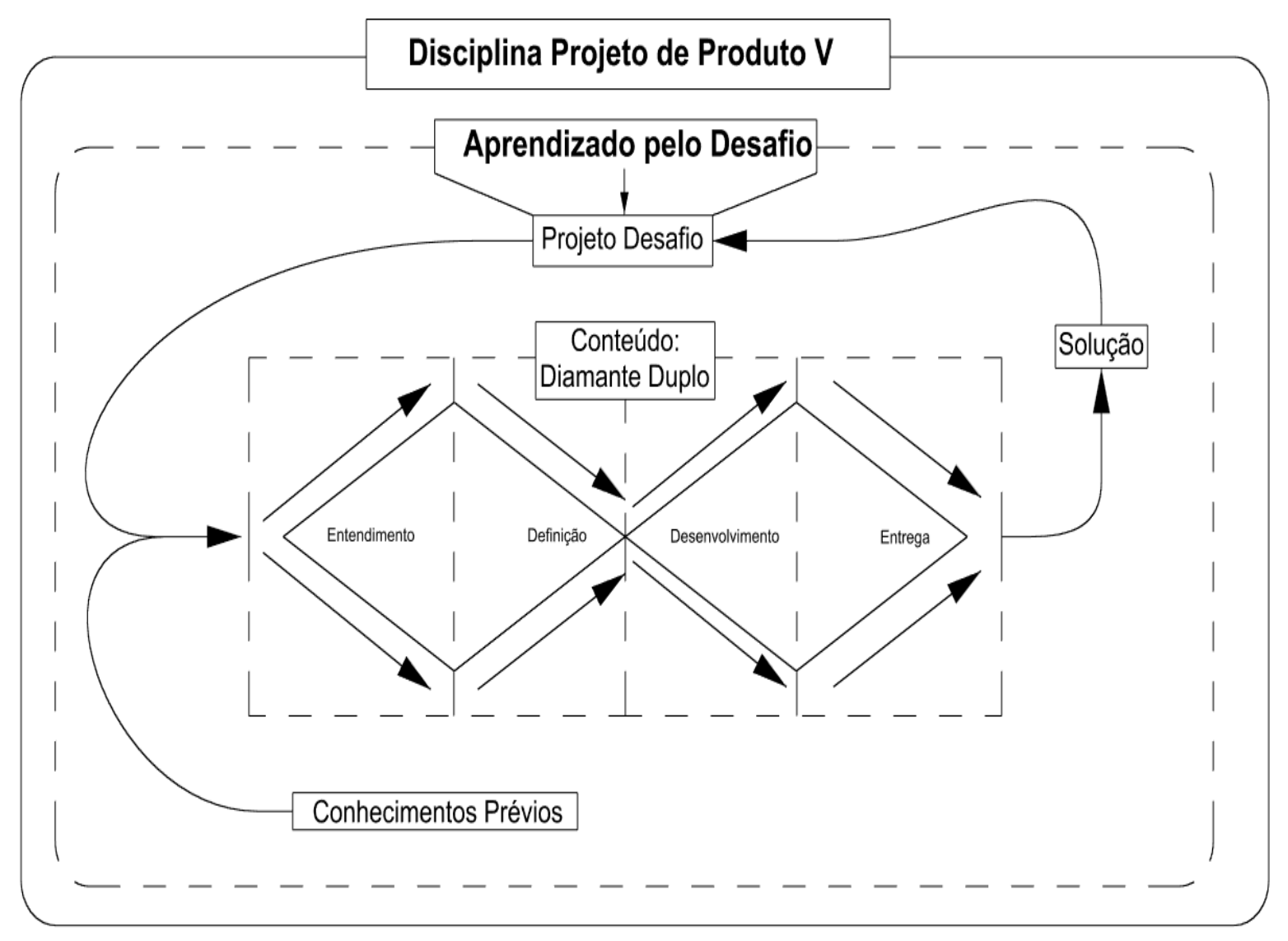

Figura 4 Metodologia esquemática praticada na disciplina de projeto de produto $V(P 5)$.

\section{DESENVOLVIMENTO}

Durante o período de um semestre letivo o Projeto-Desafio proposto aos acadêmicos foi o desenvolvimento de um case (mala) hermético e com alta resistência Saberes Pedagógicos, Criciúma, v. 3, nº 1, janeiro/junho 2019.- Curso de Pedagogia- UNESC 
mecânica. Tal desafio norteou todo andamento da disciplina P5, onde os alunos buscaram soluções a partir da utilização da metodologia Diamante Duplo. No processo de elaboração dos produtos, dentro das etapas indicadas pela metodologia aplicada, foram utilizadas diferentes ferramentas auxiliares, conforme mostra o Quadro 2.

A fim de acompanhar as manifestações de aprendizagem de cada aluno no desenvolvimento do Projeto Desafio, com especial atenção aos objetivos da disciplina P5, a avaliação efetivou-se de forma processual, levando em consideração alguns instrumentos, tanto individuais quanto coletivos, dos quais se obteve a média final dos acadêmicos. $\mathrm{O}$ desenvolvimento da disciplina seguiu as etapas pré-estabelecidas pelo Diamante Duplo:

\begin{tabular}{|l|l|l|}
\hline \multicolumn{1}{|c|}{ Etapa } & \multicolumn{1}{|c|}{ Ferramenta } & \multicolumn{1}{c|}{ Objetivo } \\
\hline Entendimento & Pesquisa com o usuário & $\begin{array}{l}\text { Entender melhor o usuário final do } \\
\text { produto e suas dificuldades. }\end{array}$ \\
\cline { 2 - 3 } & Pesquisa de mercado & $\begin{array}{l}\text { Saber os diferentes produtos existentes } \\
\text { no mercado, e buscar suas qualidades e } \\
\text { problemas. }\end{array}$ \\
\hline Desenvolvimento & Matriz morfológica & $\begin{array}{l}\text { Auxiliar na ideação e na busca de } \\
\text { alternativas inovadoras. }\end{array}$ \\
\cline { 2 - 3 } & Prototipagem rápida & $\begin{array}{l}\text { Obter modelos de avaliação de forma } \\
\text { rápida. }\end{array}$ \\
\hline
\end{tabular}

Quadro 2: Principais ferramentas auxiliares utilizadas durante o cumprimento das etapas do processo de desenvolvimento.

\subsection{Etapa de entendimento}

Nesta etapa inicial os acadêmicos aplicaram questionários de pesquisa com os possíveis usuários dos produtos alvo do projeto. As perguntas do questionário foram estabelecidas coletivamente em sala de aula, e tinham como objetivo: compreender melhor como o case seria utilizado; compreender como ocorreria seu transporte; compreender quais tipos de objetos 


\section{SABERES PEDAGÓGICOS}

Revista do Curso de Graduaçào de Pedagogia - Unesc

ISSN $2526-4559$

seriam colocados em seu interior; interpretar possíveis falhas nos produtos atualmente utilizados; interpretar possíveis especificidades dos usuários na sua utilização.

Para compreender a colocação do produto no mercado, as equipes de alunos produziram um levantamento dos produtos similares disponíveis atualmente para compra. Esta pesquisa restringiu-se ao âmbito digital, pois na região não existem lojas especializadas neste tipo de acessório, tornando-se inviável a pesquisa in loco dos objetos. Esta etapa teve participação simultânea de todas equipes envolvidas sendo que os resultados obtidos foram compilados e compartilhados entre todos, tornando-se a grande fonte de informações para o desenvolvimento dos projetos.

\subsection{Etapa de definição}

$\mathrm{Na}$ etapa de definição, com base nos dados coletados, cada aluno montou um conceito para seu possível desenvolvimento e o apresentou em forma de seminário. Esta etapa foi avaliada individualmente, e os conceitos viáveis e mais bem avaliados pelos docentes foram selecionados. Os acadêmicos foram agrupados por afinidade de projeto, sendo que cada grupo ficou responsável pelo desenvolvimento do briefing de um dos conceitos pré-selecionados. O briefing consiste em uma delineação das características e/ou funcionalidades do produto a ser trabalhado, e portanto, norteia todo o processo de desenvolvimento que segue na próxima etapa, porém, antes de finalizar a "Definição", as equipes se organizaram quanto à divisão de tarefas e as ações intermediárias necessárias para o bom andamento do projeto.

\subsection{Etapa de desenvolvimento}

A etapa iniciou com a determinação dos requisitos técnicos e morfológicos dos objetos similares existentes no mercado. Este levantamento deu origem a uma matriz morfológica contendo os produtos similares, e as soluções praticadas em cada produto para cada característica de interesse. As pesquisas realizadas nas etapas anteriores formaram a base para a criação do que chamamos de "personas", personagem fictício criado a partir dos possíveis perfis de usuários.

Saberes Pedagógicos, Criciúma, v. 3, nº1, janeiro/junho 2019.- Curso de Pedagogia- UNESC 


\section{SABERES PEDAGÓGICOS}

Revista do Curso de Graduaçào de Pedagogia - Unesc

ISSN $2526-4559$

Em geral percebeu-se que os briefings produzidos na etapa "definição" foram muito semelhantes em todas as equipes, não contendo nenhum destaque em especial, porém, a criação do personagem (persona) no início desta etapa, foi o gatilho para o distanciamento das ideias e conceitos dos grupos. Embora todos os produtos tenham características técnicas semelhantes, a análise do perfil do usuário tomou importância grandiosa nas decisões e escolhas das ideias. No desenvolvimento também foram produzidos diversos desenhos de ideias com ajuda da matriz morfológica, processo criativo chamado "ideação" é algo parecido como uma "tempestade de ideias" (brainstorm) de esboços com possíveis soluções para o produto. Ainda nesta etapa algumas equipes realizaram a fabricação de modelos primitivos de avaliação (mock-ups). A partir da ideação e dos modelos de avaliação produzidos, as equipes criaram conceitos que foram modelados digitalmente com uso das ferramentas SolidWorks e Rhinoceros.

$\mathrm{Na}$ modelagem digital observou-se a grande capacidade de algumas equipes superarem as dificuldades, pois no modelo digital é possível simular algumas funcionalidades e prever possíveis falhas. Todas as equipes envolvidas apontaram alterações primordiais para seus projetos. As observações criteriosas apontadas por algumas equipes demonstraram alto engajamento no projeto; um bom conhecimento técnico, e principalmente, uma grande sintonia com a persona criada.

Com os projetos bem adiantados, os grupos passaram para o processo de modelagem. A modelagem foi realizada basicamente com massa de modelar, MDF, e massa corrida. Os acessórios dos cases, tais como fechadura, dobradiça e demais periféricos necessários, foram produzidos por técnicas de prototipagem rápida, entre as quais podemos citar: Corte Laser e Impressão 3D com tecnologia de modelagem por deposição fundida (Fused Deposition Modeling - FDM). Ao longo da modelagem muitos detalhes sofreram alteração, porém os conceitos mantiveram-se fiéis, dando origem a modelos mais bem-acabados. Nesta etapa as equipes foram avaliadas de acordo com: a produção individual; a matriz morfológica; os modelos digitais; e a capacidade de detectar e solucionar possíveis problemas. 


\subsection{Etapa de entrega}

Esta etapa foi realizada em forma de apresentação, e teve como público convidado todos os acadêmicos do curso para os quais foram apresentados os modelos físicos dos produtos, assim como a documentação técnica do projeto, que era constituída por conceito, desenhos técnicos e modelagem digital.

Devido ao tempo demasiadamente curto e o custo oriundo da compra dos materiais, a fase final de entrega ocorreu com os modelos. Os modelos estavam devidamente acabados e pintados, representando fielmente o produto desenvolvido. Todos continham um grande número de detalhes técnicos e geométricos que proporcionaram uma identidade única aos produtos. Verificou-se que as equipes se esforçaram para realizar uma boa apresentação, sendo que algumas trataram a apresentação como um lançamento do produto, produzindo ainda a marca, logomarca e folders de apresentação para seus produtos.

$\mathrm{Na}$ avaliação da entrega foram considerados critérios individuais e coletivos tais como: participação; execução do modelo; apresentação; mobilidade do produto; adequação ao briefing e ergonomia. O acompanhamento da aprendizagem também foi efetivado através da avaliação da documentação técnica organizada pelos alunos durante a pesquisa proposta no Projeto Desafio, esta foi entregue em forma de artigo científico contendo informações tais como: tabela morfológica, pesquisa aplicada, conceito, desenhos técnicos, modelagem digital, e demais informações relevantes ao processo de desenvolvimento. A Figura 5 apresenta esquematicamente o desenvolvimento da disciplina, com as atividades realizadas, e os critérios avaliados em cada uma das fases. 


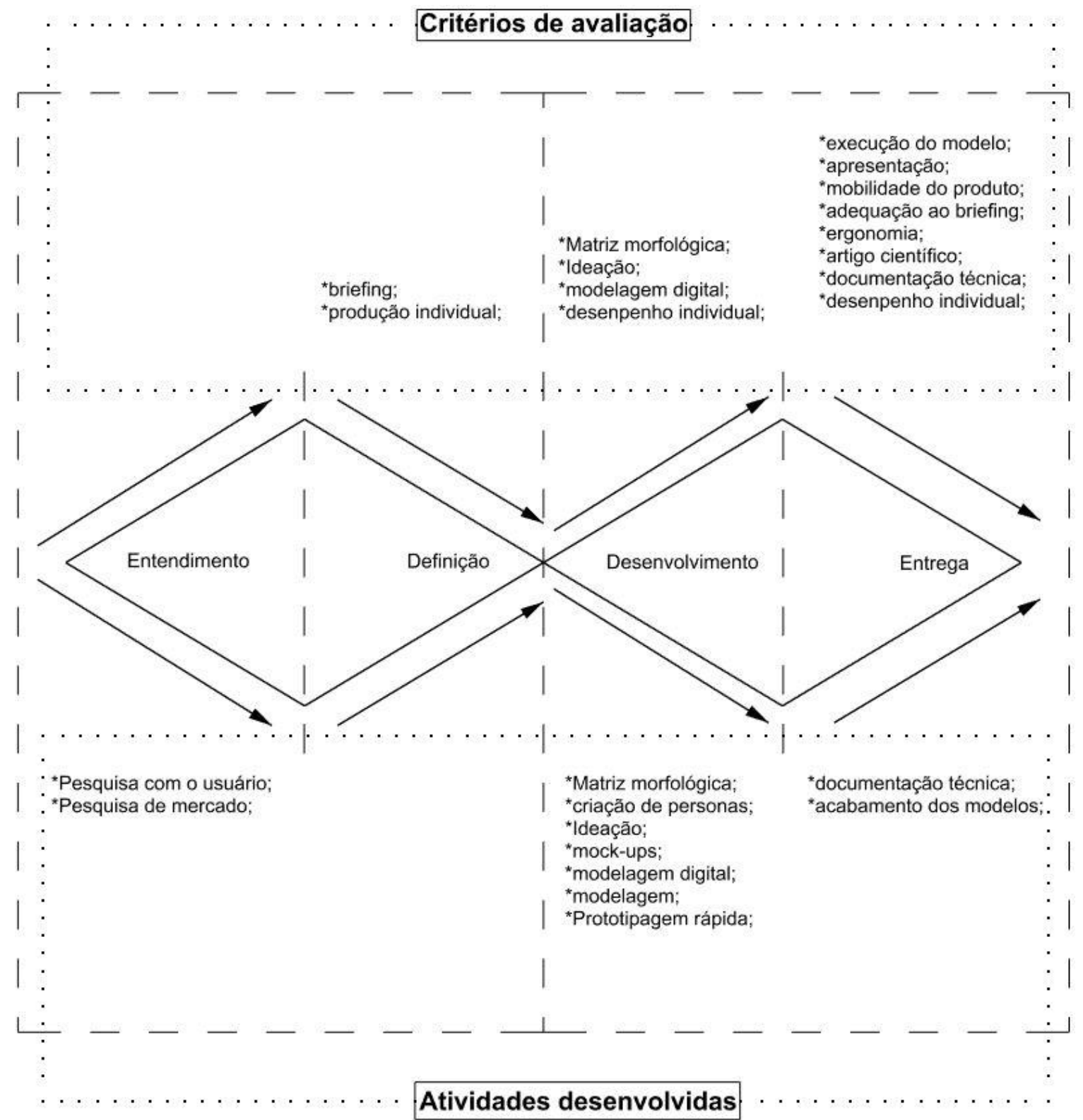

Figura 5: passo a passo do desenvolvimento da disciplina, com as atividades realizadas, e os critérios avaliados em cada uma das fases

\section{CONSIDERAÇÕES FINAIS}

A aplicação de uma metodologia envolvendo ensino, pesquisa e extensão mostrouse totalmente adequada à disciplina de Projeto de Produto V (P5). As atividades realizadas no Projeto Desafio, trouxeram uma grande versatilidade e dinâmica ao desenvolvimento da 


\section{SABERES PEDAGÓGICOS}

Revista do Curso de Graduaçào de Pedagogia - Unesc

ISSN 2526-4559

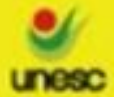

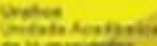

disciplina, estimulando as diversas competências e habilidades requeridas ao profissional da área de Design.

O grande número de ideias diferentes que circularam pelos grupos proporcionou aos acadêmicos momentos de reflexão e troca de experiências sobre os produtos, a observação dos acertos e erros das várias equipes de trabalho oportunizou o encontro de soluções dos problemas confrontados até a apresentação final do produto. Avaliando processualmente o cumprimento das etapas do Projeto Desafio pelas equipes, foi possível acompanhar o aprendizado dos alunos, em diálogo constante.

Tamanha diversidade em sala de aula tornou o trabalho de professores e alunos exaustivos devido aos incessantes ciclos de atendimentos às equipes, contudo considera-se que a metodologia de trabalho com projetos pedagógicos foi imprescindível para alcançar os objetivos institucionais, do curso, e da disciplina.

\section{REFERÊNCIAS}

DONOSO-GARCIA, Pedro F.; TÔRRES, Leonardo A. Borges. "Ensino orientado ao projeto desafio: uma experiência para o ensino de controle, instrumentação e eletrônica". In:Anais do XXXV Congresso Brasileiro de Educação em Engenharia, Curitiba, v. 05, n. 3, p.1-15, set. 2007.

DEMO, Pedro. Educar pela pesquisa. 2. ed. Campinas: Autores Associados, 1997. 128 p.

FINK, Flemming K.. Problem-Based Learning in engineering education: a catalyst for regional industrial development. World Transactions On Engineering And Technology

Education, [s.i], v. 1, n. 1, p.1-4, 2002.

DESIGN COUNCIL (Inglaterra). A study of the design process. Disponível em: <http://www.designcouncil.org.uk/sites/default/files/asset/document/ElevenLessons_Design_ Council (2).>. Acesso em: 07 set. 2016.

MAYER, Robert. How engineers learn: a study of problem-based learning in the engineering classroom and implications for course design. 2013. 92 f. Dissertação (Mestrado) - Curso de Master Of Science, Iowa State University, Ames, 2013. Disponível em: $<$ http://lib.dr.iastate.edu/cgi/viewcontent.cgi? article=4209\&context=etd $>$. Acesso em: 24 ago. 2016.

Saberes Pedagógicos, Criciúma, v. 3, nº1, janeiro/junho 2019.- Curso de Pedagogia- UNESC 
SANTOS, Célio Teodorico dos. Requisitos de linguagem do produto: uma proposta de estruturação para as fases iniciais do PDP. 2009. 197 f. Tese (Doutorado) - Curso de Engenharia Mecânica, Universidade Federal de Santa Catarina, Florianópolis, 2009.

ZAVADIL, Priscila et al. Possibilidades de uso da matriz morfológica no processo de geração de alternativas em design. Blucher Design Proceedings, Gramado, v. 1, n. 4, p.1-12, out. 2014. Disponível em <http://pdf.blucher.com.br.s3-sa-east-

1.amazonaws.com/designproceedings/11ped/00925.pdf>. Acesso em: jul. de 2017. 